\title{
Synthesis and Characterization of $\mathrm{Al}_{2} \mathrm{O}_{3}$-Doped LaFeO 3 Thick Film Ceramics for Ethanol Gas Sensing Application
}

\section{ENDI SUHENDI ${ }^{1 *}$, NENG ASTRI LIDIAWATI', DANI GUSTAMAN SYARIF² and ANDHY SETIAWAN ${ }^{1}$}

\author{
${ }^{1}$ Physics Department, Universitas Pendidikan Indonesia, Jl. Dr. Setiabudhi 229, Bandung (40154), Indonesia \\ ${ }^{2}$ PSTNT-BATAN, JI. Tamansari 71, Bandung (40132), Indonesia. \\ ${ }^{*}$ Corresponding author E-mail: endis@ upi.edu \\ http://dx.doi.org/10.13005/ojc/350134
}

Received: December 29, 2018; Accepted: February 09, 2019)

\begin{abstract}
Preparation and characterization of $\mathrm{Al}_{2} \mathrm{O}_{3}$-dopped $\mathrm{LaFeO}_{3}$ thick film ceramics for ethanol gas sensor applications has been conducted. $\mathrm{LaFeO}_{3}$ ceramics were made by co-precipitation method with doping variation of $\mathrm{Al}_{2} \mathrm{O}_{3} 0 \%$ and $3.75 \%$ mole of the main ingredients $\mathrm{LaFeO}_{3}\left(\mathrm{La}_{2} \mathrm{O}_{3}\right.$ and $\left.\mathrm{Fe}_{2} \mathrm{O}_{3}\right)$. Screen printing technique was employed to make thick film ceramics of $\mathrm{LaFeO}_{3}$ and $\mathrm{Al}_{2} \mathrm{O}_{3}$-dopped $\mathrm{LaFeO}_{3}$. The ceramics were calcined at temperature of $60^{\circ} \mathrm{C}$. The analysis results of the characteristics of crystals using X-Ray Difraction (XRD) showed that the made ceramics made had cubic phase with a lattice parameter $a=b=c=39.52 \mathrm{~nm}$. The addition of $3.75 \%$ mole of $\mathrm{Al}_{2} \mathrm{O}_{3}$ did not change the crystal phase and lattice parameter values of $\mathrm{LaFeO}_{3}$. The crystallite size of $\mathrm{LaFeO}_{3}$ was $52.17 \mathrm{~nm}$ while the crystallite size of $\mathrm{Al}_{2} \mathrm{O}_{3}$-doped $\mathrm{LaFeO}_{3}$ was $44.52 \mathrm{~nm}$. The analysis results of morphological structure ceramics of $\mathrm{LaFeO}_{3}$ and $\mathrm{Al}_{2} \mathrm{O}_{3}$-doped $\mathrm{LaFeO}_{3}$ using Scanning Electron Microscopy (SEM) possessed a grain size of each $0: 40 \mu \mathrm{m}$ and $0.25 \mu \mathrm{m}$. The electrical characterization results of $\mathrm{LaFeO}_{3}$ thick film ceramics indicated the sensitivity of the sensor increased along with the addition of ethanol gas concentration. The maximum sensitivity value of $\mathrm{LaFeO}_{3}$ thick film ceramics ceramic thick film $\mathrm{LaFeO}_{3}$ and $\mathrm{Al}_{2} \mathrm{O}_{3}$-doped $\mathrm{LaFeO}_{3}$ at $300 \mathrm{ppm}$ was 4.34 at $330^{\circ} \mathrm{C}$ and 6.08 at $350^{\circ} \mathrm{C}$. The thick film ceramics with the addition of $3.75 \%$ mole of $\mathrm{Al}_{2} \mathrm{O}_{3}$ has a higher sensitivity and potential to be used as ethanol gas sensor.
\end{abstract}

Keywords: $\mathrm{LaFeO}_{3}, \mathrm{Al}_{2} \mathrm{O}_{3}$-doped $\mathrm{LaFeO}_{3}$, Co-precipitation, Screen Printing, Film Thickness, Ethanol Gas Sensor.

\section{INTRODUCTION}

Gas sensors are electro-chemical sensors which provide an electrical signal in response to chemical interaction with the gas ${ }^{1}$. A gas sensor enables to detect environmental changes by changing the amount of chemical into electrical quantities ${ }^{2,3}$. Ethanol gas sensor $\left(\mathrm{C}_{2} \mathrm{H}_{6} \mathrm{O}\right)$ is one of the gas sensors needed for daily activities such as in the perfume industry ${ }^{4}$, food and beverages ${ }^{5}$.

Perovskite-type oxides with an $\mathrm{ABO}_{3}$ perovskite structure (A: alkali metal cations or alkaline-earth metal; B: transition metal cations)

This is an Open Access article licensed under a Creative Commons license: Attribution 4.0 International (CC- BY). Published by Oriental Scientific Publishing Company @ 2018

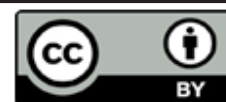


has been widely used as raw material for gas sensor for it has high temperature stability and selectivity to different gases ${ }^{6,7,8}$. The example of perovskite-type oxides is lanthanum ferrite $\left(\mathrm{LaFeO}_{3}\right)$ which is derived from synthesis of $\mathrm{La}_{2} \mathrm{O}_{3}$ and $\mathrm{Fe}_{2} \mathrm{O}_{3}$. Metal oxides can be obtained from purified yarosit mineral. This yarosit mineral are easily found in Indonesia, on the north coast of the Java, Sumatra, Kalimantan and Bangka Island ${ }^{9}$.

The purified yarosit mineral contains $\mathrm{Fe}_{2} \mathrm{O}_{3}$ amounting to $91.30 \%$ by weight, $3.30 \%$ of $\mathrm{Al}_{2} \mathrm{O}_{3}$, $2.05 \%$ of $\mathrm{SiO}_{2}, 3.02 \%$ of $\mathrm{TiO}_{2}, 0.16 \%$ of $\mathrm{CaO}$ and $0.12 \%$ of $\mathrm{MnO}^{10}$. Since it has a large content of iron, the purified yarosit mineral has potential as an industrial material that is used as the base material for thick film ceramics to apply gas sensors. Research on the $\mathrm{LaFeO}_{3}$ ethanol gas sensor with $\mathrm{Fe}_{2} \mathrm{O}_{3}$ as the basic materials, the yarosit purification result has been performed and the results show that the material is sensitive to the presence of ethanol gas ${ }^{5,11}$.

The effect of each ingredient contained in yarosit purification result has not been recognized. To determine the effect of the minerals, the addition of purified yarosit $\mathrm{Al}_{2} \mathrm{O}_{3}$ was done as much as $3.75 \%$ mole or equal to $1.6 \%$ by weight of the main ingredient of $\mathrm{LaFeO}_{3}$. This concentration is a concentration below the concentration of $\mathrm{Al}_{2} \mathrm{O}_{3}$ contained in yarosit mineral purification results. The materials used in the manufacture of $\mathrm{Al}_{2} \mathrm{O}_{3}$-dopped $\mathrm{LaFeO}_{3}$ are pure materials so that there are no impurities other than in ceramics. Crystal characteristics, morphology and electrical characteristics of thick film ceramics will be analyzed and compared with $\mathrm{Al}_{2} \mathrm{O}_{3}$-dopped $\mathrm{LaFeO}_{3}$. If the addition of $3.75 \%$ mole of $\mathrm{Al}_{2} \mathrm{O}_{3}$ shows a positive influence on $\mathrm{LaFeO}_{3}$, the content of $\mathrm{Al}_{2} \mathrm{O}_{3}$ in the purified yarosit shall not be eliminated so it will reduce the cost of the purification process.

\section{Materials and methods}

\section{Materials}

The materials used in this study are, Lanthanum (III) chloride heptahydrate $\left(\mathrm{LaCl}_{3.7} \mathrm{H}_{2} \mathrm{O}\right.$, Iron (III) oxide $\left(\mathrm{Fe}_{2} \mathrm{O}_{3}\right)$ and aluminum chloride $\left(\mathrm{LaCl}_{3}\right)$. These materials are determined severity based chemical calculations. The powder of $\mathrm{LaFeO}_{3}$ is synthesized from powder and mole ratio of $1: 1$. The powder of $\mathrm{Al}_{2} \mathrm{O}_{3}$-dopped $\mathrm{LaFeO}_{3}$ was synthesized from $\mathrm{LaCl}_{3}, 7 \mathrm{H}_{2} \mathrm{O}_{3}$ and $\mathrm{laCl}_{3}$ comparing with each mole were 13:13;1 respectively.

\section{Preparation of powder}

$\mathrm{LaFeO}_{3}$ and $\mathrm{Al}_{2} \mathrm{O}_{3}$-dopped $\mathrm{LaFeO}_{3}$ powder were made by using co-precipitation method. First, all ingredients were dissolved with each solvent. $\mathrm{LaCl}_{3},{ }_{7} \mathrm{H}_{2} \mathrm{O}$, and $\mathrm{AlCl}_{3}$ were dissolved by using distilled water (aquades) and $\mathrm{Fe}_{2} \mathrm{O}_{3}$ was dissolved with $\mathrm{HCl} 10 \mathrm{M}$. After each ingredient was dissolved, all solution was mixed and was added by $\mathrm{NH}_{4} \mathrm{OH}$ solution so that the precipitate of $\mathrm{LaFeO}_{3}$ and $\mathrm{Al}_{2} \mathrm{O}_{3}-$ dopped $\mathrm{LaFeO}_{3}$ was formed. The precipitate was dried at a temperature of $100^{\circ} \mathrm{C}$ and was calcined at a temperature of $800^{\circ} \mathrm{C}$ for 2 hours. The results of calcination were crushed and screened to the same nano-sized powder.

\section{Preparation thick film}

Each $\mathrm{LaFeO}_{3}$ and $\mathrm{Al}_{2} \mathrm{O}_{3}$-dopped $\mathrm{LaFeO}_{3}$ powder was mixed with Organic Vehicle (OV) with a ratio of $70 \%$ and $30 \%$ in order to form a paste. The pasta was coated on a substrate of alumina which has been coated with silver using screen printing method and baked at a temperature of $600^{\circ} \mathrm{C}$ for $2 \mathrm{~h}$ to produce $\mathrm{LaFeO}_{3}$ and $\mathrm{Al}_{2} \mathrm{O}_{3}$-dopped $\mathrm{LaFeO}_{3}$ thick film ceramics.

\section{Characterization of thick film}

Crystal characteristics of $\mathrm{LaFeO}_{3}$ and $\mathrm{Al}_{2} \mathrm{O}_{3}-$ dopped $\mathrm{LaFeO}_{3}$ thick film ceramics were analyzed using X-Ray Difractrometer (XRD PRO series, $\lambda=1.540598 \AA$, PAN), thick film ceramic surface morphology was analyzed using Scanning Electron Microscope (SEM, JEOL-6360LA) and electrical characteristics of thick film ceramics were measured by using a set of tools chamber gas. The measurement of the electrical properties was done by heating the thick film ceramics from room temperature to a temperature of $360^{\circ} \mathrm{C}$. When the resistance value was read, every increase in temperature of $5 \square$, the temperature and the resistance value were recorded. Electrical characteristic testing was done without using gas (ambient state) and using ethanol gas at a concentration of 100 ppm, 200 ppm to 300 ppm.

\section{RESULTS AND DISCUSSION}

\section{Characteristics of Crystals}

Graph of the XRD $\mathrm{LaFeO}_{3}$ and $\mathrm{Al}_{2} \mathrm{O}_{3}-$ dopped $\mathrm{LaFeO}_{3}$ thick film ceramics is shown in Fig. 1. From the graph it can be seen the diffraction angle and orientation of the area corresponding to the database crystallographic open database (COD) 
No.96-154-2033. The formed phase crystals are the same phase that is cubic with lattice parameters a $=b=c=3,926 \mathrm{~A}$. It can be seen from the graph that the relationship between the intensity and $2 \theta$ had the same diffraction pattern. The addition of $3.75 \%$ mole of $\mathrm{Al}_{2} \mathrm{O}_{3}$ did not change the phase and the lattice parameter of $\mathrm{LaFeO}_{3}$ thick film ceramics.

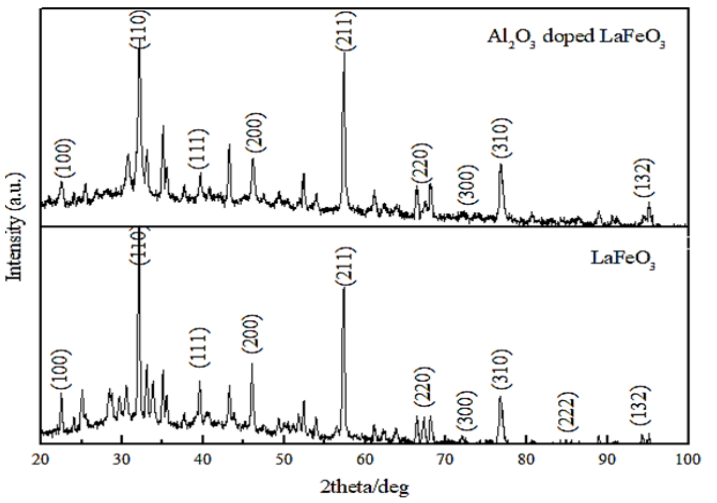

Fig. 1. XRD pattern of $\mathrm{LaFeO}_{3}$ and $\mathrm{Al}_{2} \mathrm{O}_{3}$ doped $\mathrm{LaFeO}_{3}$

The average size of the crystals can be calculated using the Debye-Scherrer equation as follows ${ }^{7}$ :

$$
D=\frac{0,9 \lambda}{B \cos \theta}
$$

$D$ is the size of the crystal in the $(\mathrm{nm}), \lambda$ is the wavelength used in the test XRD $(\mathrm{nm})$, and $B$ is the peak half width in radians, and $\theta$ is the angle position crests. The average of crystallite size of $\mathrm{LaFeO}_{3}$ and $\mathrm{Al}_{2} \mathrm{O}_{3}$-dopped $\mathrm{LaFeO}_{3}$ thick film ceramics are respectively $52.17 \mathrm{~nm}$ and $44.52 \mathrm{~nm}$. Crystallite sizes shrink when added to. $\mathrm{Al}_{2} \mathrm{O}_{3}$ doping.

\section{The Surface Morphology}

SEM test results of $\mathrm{LaFeO}_{3}$ and $\mathrm{Al}_{2} \mathrm{O}_{3}-$ dopped $\mathrm{LaFeO}_{3}$ thick film ceramics can be seen in Figure 2.

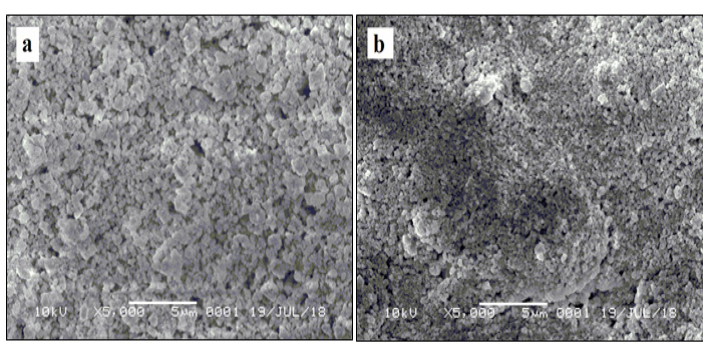

Fig. 2. Morphology structure of thick films of ceramics (a) $\mathrm{LaFeO}_{3}$ and (b) $\mathrm{Al}_{2} \mathrm{O}_{3}$-doped $\mathrm{LaFeO}_{3}$
The effect of the addition can be seen from the grain size of each ingredient. The surface of $\mathrm{LaFeO}_{3}$ and $\mathrm{Al}_{2} \mathrm{O}_{3}$-dopped $\mathrm{LaFeO}_{3}$ thick film ceramics has almost the same (uniform) grain sizes with the size $0.40 \mu \mathrm{m}$ and $0.25 \mu \mathrm{m}$ each. The grain size decreases when added by $\mathrm{Al}_{2} \mathrm{O}_{3}$. This is due to the addition of $3.75 \%$ mole of $\mathrm{Al}_{2} \mathrm{O}_{3}$ causing the particles of $\mathrm{Al}_{2} \mathrm{O}_{3}$ were segregated at the border of the grain so that the grain size of $\mathrm{Al}_{2} \mathrm{O}_{3}$ can be reduced resulting in contact among the grains become mutually bounding. Fig. 2 also shows the pores of $\mathrm{LaFeO}_{3}$ doped by $\mathrm{Al}_{2} \mathrm{O}_{3}$ that seem smaller and few.

\section{Electrical Properties}

Figure 3 shows a graph of the temperature with a thick film ceramic resistance value. The resistance value decreases as the operating temperature increases. This is in accordance with semiconductor characteristic that is the semiconductor is lowering barriers exponentially when the ambient temperature increases ${ }^{12}$.
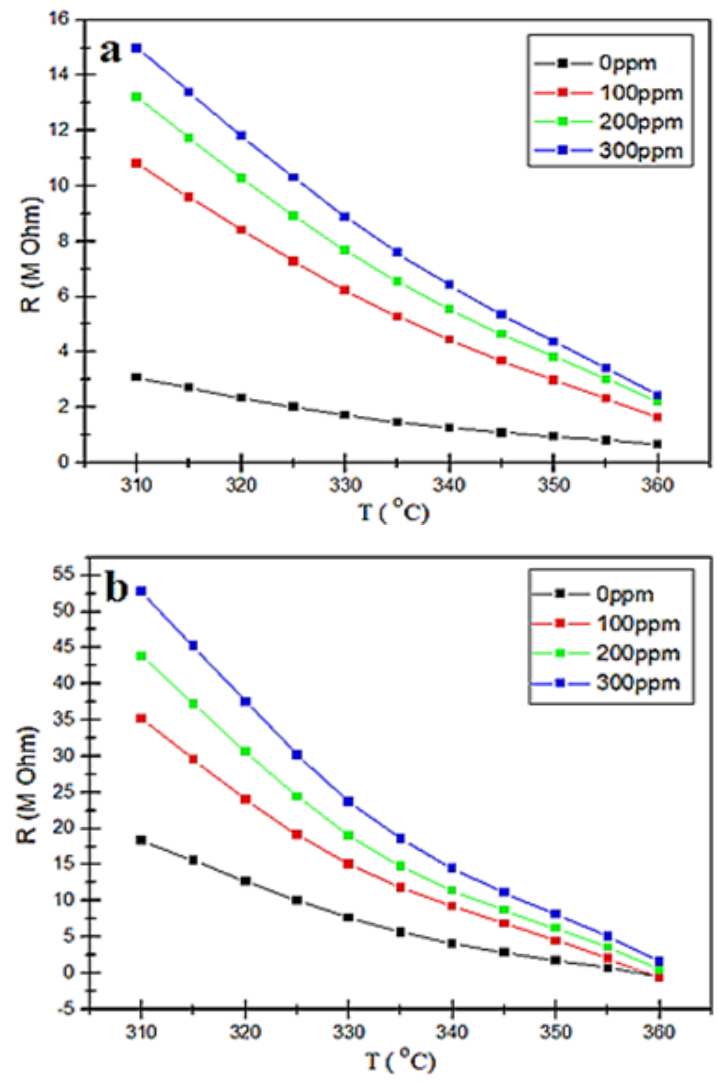

Fig. 3. Graph of functional resistance of temperature of thick films ceramics (a) $\mathrm{LaFeO}_{3}$ and (b) $\mathrm{Al}_{2} \mathrm{O}_{3}$ doped $\mathrm{LaFeO}_{3}$ 


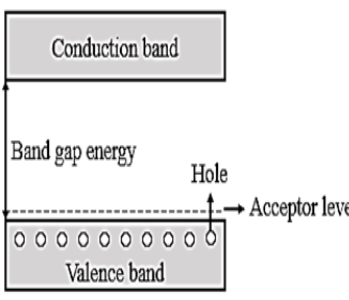

(a)

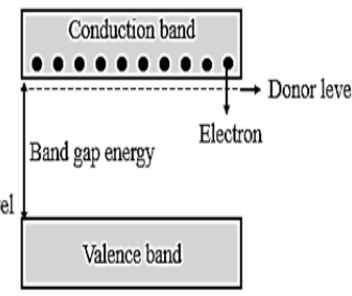

(b)
Fig. 4. The band gap energy structure of semiconductor (a) p-type and (b) n-type.

For the p-type semiconductor, at low temperatures electrons in the valence band will move to the level of the acceptor producing holes in the valence band, whereas the conduction band electrons are not free because it requires a fairly high energy (thermal energy). Concentration of electric charge carriers was unbalanced, the amount of holes are much larger than free electrons. For the n-type semiconductor, at low temperatures, the electrons at donor level can be to the level of conduction into free electrons, while the electrons in the valence band cannot move into the conduction band since it requires considerable energy. In these circumstances, the concentration of electric charge was not balanced; the amounts of free electrons are much larger than the hole. Along with the increase of temperature on semiconductor material the chance of occurrence process of atom ionization of semiconductor crystal compiler will increase, thus there will be electrons at valence band which moved to conduction band so the free electron concentration will increase as well. The process of electron excitation to the conduction band will leave a hole in the valence band ${ }^{13}$. The more electrons move to the conduction band, the easier thick film ceramics in conducting the electric current so that the resistance value will be smaller.

\section{The sensitivity and the sensor mechanism}

Thick film ceramic sensitivity values are calculated using equation $(2)^{14}$ :

$S=\frac{\left(R_{g}-R_{a}\right)}{R_{a}}$

Where $S$ is the sensitivity of the sensor, $\mathrm{R}_{g}$ is the resistance when the gas contained ethanol $(M \Omega)$, and $R_{a}$ is the resistance at ambient circumstances $(\mathrm{M} \Omega)$.
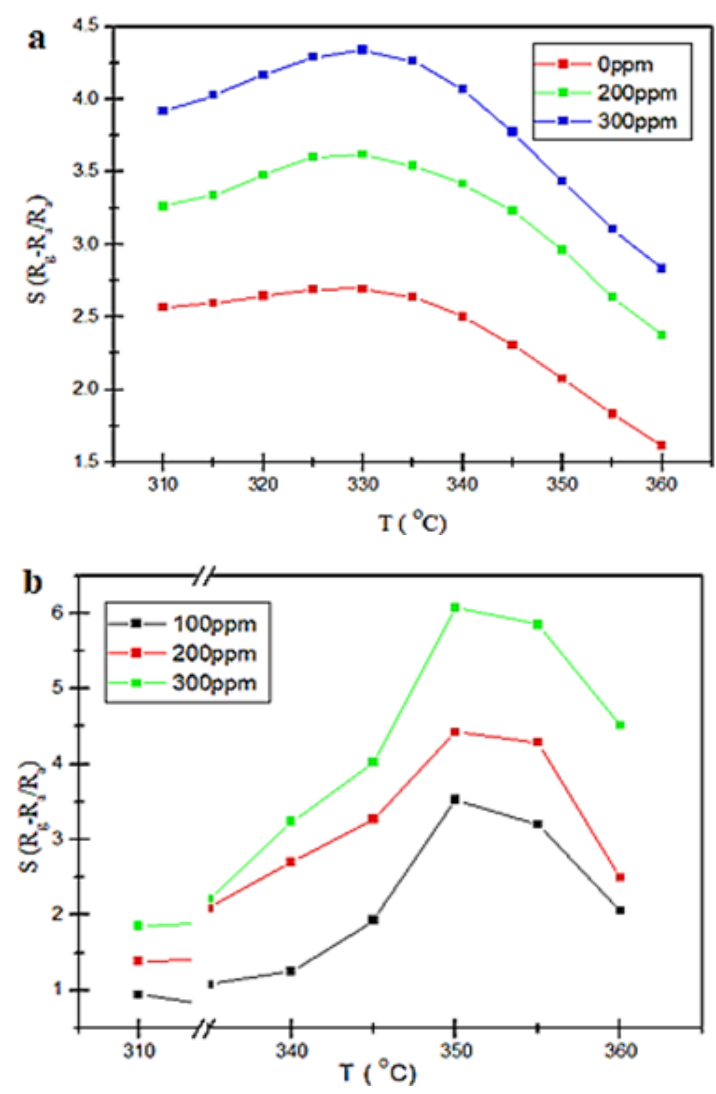

Fig. 1. Graph of sensitivity function of temperature of thick film ceramics (a) $\mathrm{LaFeO}_{3}$ and (b) $\mathrm{Al}_{2} \mathrm{O}_{3}$ doped $\mathrm{LaFeO}_{3}$

At the same temperature, the resistance value increases along with increasing the concentration of ethanol gas. Since ethanol gas is a reducing gas ${ }^{14,15}$ it is known that $\mathrm{LaFeO}_{3}$ and $\mathrm{Al}_{2} \mathrm{O}_{3}$-dopped $\mathrm{LaFeO}_{3}$ thick film ceramics has the characteristics as a p-type semiconductor (hole majority carrier) for materials with excess holes will react towards reduction with ethanol gas resulting in decreasing the gas flow characterized by an increased resistance of the material. The increase of the value of this resistance occurs because the more gas is adsorbed, the number of atoms/ions of oxygen in the thick film ceramics increases and the number of electrons decreases. The more the concentration of ethanol gas, the higher the potential barrier which were formed so the electron is hard to be excited from the valence band to the conduction band ${ }^{16,17}$.

The influence of operating temperature on the sensitivity of $\mathrm{LaFeO}_{3}$ and $\mathrm{Al}_{2} \mathrm{O}_{3}$-dopped $\mathrm{LaFeO}_{3}$ thick film ceramics at 100, 200 and 300ppm ethanol gas was shown in Fig. 5 (a) and (b). The 
gas response increased along with increasing temperature of operation and achieved maximum sensitivity at the operating temperature $330^{\circ} \mathrm{C}$ for $\mathrm{LaFeO}_{3}$ thick film ceramics and $350^{\circ} \mathrm{C}$ for $\mathrm{Al}_{2} \mathrm{O}_{3}-$ dopped $\mathrm{LaFeO}_{3}$ and then decreased along with increasing operating temperature.

At high temperatures the oxygen molecule was adsorbed the surface of thick film. The order of the processes involved in the absorption of oxygen can be described by the following equation ${ }^{15}$ :

$\mathrm{O}_{2}$ (gas) $\leftrightarrow \mathrm{O}_{2}$ (ads)

$\mathrm{O}_{2}$ (ads) $+\mathrm{e}^{-} \leftrightarrow \mathrm{O}_{2}$ (ads)

$\mathrm{O}_{2}^{-}$(ads) $+\mathrm{e}^{-} \leftrightarrow 2 \mathrm{O}^{-}$(lattice)

in this state the electrons present in the valence band obtain a number of thermal energy that can be excited into the conduction band and leave holes in the valence band (Figure 6 (a).

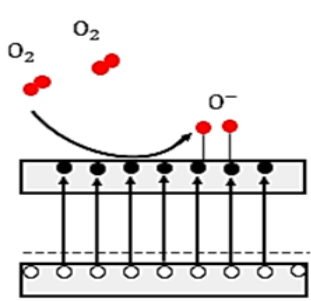

(a)

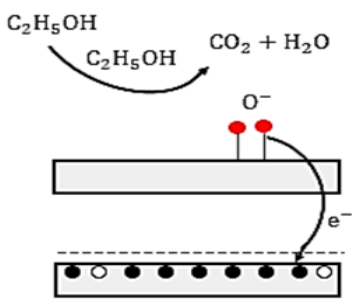

(b)
Fig. 6. Adsorption -oxidation-desorption process (a) ambient and (b) ethanol exposed gases

In Fig. 6 (a) the oxygen molecules were adsorbed on the surface of the thick film ceramics will be ionized because it binds to electrons in the conduction band that are shown by equations 4 and 5 . In addition to the formation of ion $\mathrm{O}^{-}$this absorption of oxygen causes forming a depletion layer around the grain boundaries. Depletion layer thickness is determined by the amount of oxygen and intrinsic electrons contained in the material surface. Layer depletion at grain boundaries generate potential barrier so that the grain boundaries impede the movement of electrons ${ }^{17}$.

At the time of $\mathrm{LaFeO}_{3}$ and $\mathrm{Al}_{2} \mathrm{O}_{3}$-dopped $\mathrm{LaFeO}_{3}$ thick film ceramics exposure to ethanol gas, the ethanol gas molecules will react with oxygen gas molecules on the surface of thick film ceramics that has been ionized into $\mathrm{O}^{-}$and $\mathrm{O}^{2-}$ produced $2 \mathrm{CO}_{2}$ and
$3 \mathrm{H}_{2} \mathrm{O}$ in accordance with Fig. 6 (b). The mechanism of the gas sensor is basically an oxidation-reduction reaction on the surface of the material. $\mathrm{O}^{2-}$ was absorbed accelerating this following reaction ${ }^{14}$ :

$\mathrm{C}_{2} \mathrm{H}_{5} \mathrm{OH}+6 \mathrm{O}^{\mathrm{n}-} \rightarrow 2 \mathrm{CO}_{2}+3 \mathrm{H}_{2} \mathrm{O}+6 \mathrm{ne}^{-}$

This reaction caused the increase in resistance value that was indicated by the higher potential barrier (Fig. 7 (b) as the detached electrons return to the valence band so that the number of holes in the valence band was reduced ${ }^{14,15}$.

Condition

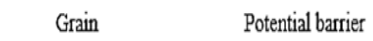

(a) Ambient

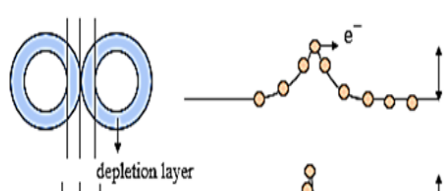

(b) Presence of reducing gases

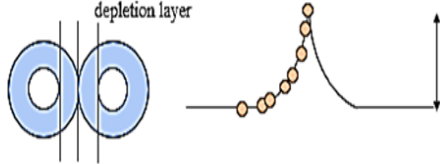

(c) Presence of oxidizing gases
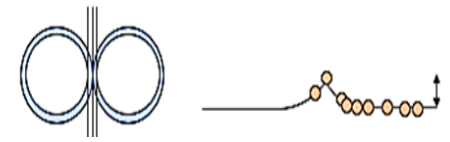

Fig. 7. The potential barrier of the p-type semiconductor in various condition

\section{CONCLUSION}

The powder of $\mathrm{LaFeO}_{3}$ and $\mathrm{Al}_{2} \mathrm{O}_{3}$-dopped $\mathrm{LaFeO}_{3}$ has been made by employing co-precipitation method. Thick film ceramics were generated through screen printing method. The XRD results showed $\mathrm{LaFeO}_{3}$ and $\mathrm{Al}_{2} \mathrm{O}_{3}$-dopped $\mathrm{LaFeO}_{3}$ thick film ceramics has a cubic phase with a lattice parametera $=b=c=39.52 \mathrm{~nm}$. The crystallite size before and after the addition of doping was shrunk from $52.17 \mathrm{~nm}$ to $44.52 \mathrm{~nm}$. The addition of $\mathrm{Al}_{2} \mathrm{O}_{3}$ minimized the size of grain from 0:40 $\mu \mathrm{m}$ and 0.25 $\mu \mathrm{m}$, increased the value of electric resistance and increase the operating temperature. Gas sensors doped by $\mathrm{Al}_{2} \mathrm{O}_{3}$ have a higher sensitivity of the gas sensor without the addition of doping.

\section{ACKNOWLEDGMENT}

This work was financially supported by "Hibah Penelitian Terapan Unggulan Perguruan Tinggi" Research Grants in the fiscal year 2018. 


\section{REFERENCES}

1. Yadav, AK; Singh, RK; Singh, P. Sensors and Actuators B: Chemical., 2016, 229, 25-30.

2. Hiskia. BATAN., 2007, 7-18.

3. Sujitno, T., Atmono, T., Sayono, S., \& Susita, L. BATAN., 2006, 9(2).

4. Rahimah S .; Sharif DG; Suhendi E. BATAN., 2011, 329-322.

5. Suhendi, E .; Witra; Hasanah, L .; Sharif, DG AIP., 2017, 1848.

6. Cyza, A .; Kopia, A .; Cieniek, lbs .; Kusinski, J. Materials Today., 2016, 3(8), 2707-2712.

7. Haron, W .; Wisitsoraat, A .; Wongnawa, S. (2015).Prepared Oxide Nanocrystalline perovskite $\mathrm{LaFeO}_{3}$ at Lower Temperature with Improved Ethanol Gas Sensoring. ICBNE., 2015, 10-14.

8. Khetre, SM; Chopade, AU; Khilare, CJ; Kulal, SR .; Jadhav, HV; Jagadale, PN; Bamane, SR $J$ of Shivaji Union (Sci \& Tech)., 2014, 41(2), 250-5347.
9. Taufik, D.; Sharif, DG; Karim, S. BATAN., 2007.

10. Suhendi, E .; Novia, H .; Sharif, DG; Prajitno, D. $H$, Proceedings of the National Seminar on Research, Education and Application of Mathematics, Faculty of Science, University of Yogyakarta., 2010.

11. Ariyani, NI; Sharif, DG; Suhendi, E. IOP., 2018, 384.

12. Yacoobi, BG Plenum., 2003.

13. Barsoum, MW Institute of Physics., 2003.

14. Thuy, NT; Minh, DL; Giang, HT; Toan, NN Hindawi., 2014.

15. Benali, A .; Azizi, S .; Bejar, M .; Dhahri, E .; Graça, MFP Ceramics International., 2014, 40(9), 14367-14373.

16. Shankar, P .; Rayappan, JBB Sci. Lett. J., 2015, 4, 126.

17. Balaguru, RJB .; Jeyaprakash, BG Tamil Nadu., 2012. 